\title{
Tratamento De ESgoto PARA USO NA AGRICULTURA dO SEMI-ÁRIDO NORDESTINO
}

\section{TREATMENT OF SEWAGE FOR USE IN THE AGRICULTURE OF THE SEMI-ARID NORTH EAST BRAZIL}

\begin{abstract}
JoSÉ TAVARES DE SOUSA
Mestre em Engenharia Civil, UFPB. Doutor em Hidráulica e Saneamento, USP. Professor da Universidade Estadual da Paraíba (UEPB). Diretor do CCT/ UEPB

\section{ADRIANUS CORNELIUS VAN HAANDEL}

$\mathrm{PhD}$ em Engenharia Civil África do Sul. Pós-Doutorado Universidade Agrícola de Wageningen, Holanda. Professor da Universidade Federal da Paraíba. Coordenador do PROSAB/UFPB

\section{PAULA FrassinetTI FEITOSA CAVALCANTI}

Mestre em Engenharia Civil, UFPB. PhD na Wageningen University. Professora da Engenharia civil, Universidade Federal da Paraíba
\end{abstract}

\section{ANNA MitCHIELLE FERNANDES DE FIGUEIREDO \\ Mestranda do PRODEMA UFPB/UEPB}

Recebido: 24/01/05 Aceito: 22/08/05

\section{RESUMO}

O presente trabalho relata o desempenho de três sistemas de póstratamento de efluente anaeróbio: wetland, leito de brita não vegetado e lagoas de polimento, operados com o objetivo de produzir efluentes para reúso na agricultura do semi-árido do Nordeste do Brasil. Para tanto, foram investigados os parâmetros: $\mathrm{DQO}, \mathrm{pH}$, sólidos e suas fraçōes, macronutrientes, ovos de helmintos e indicadores de contaminação fecal. Apenas a Lagoa de Polimento produziu um efluente compatível com as recomendações da OMS para irrigação irrestrita. Os efluentes dos sistemas wetland e leito de brita não vegetado, embora isentos de ovos de helmintos, apresentaram concentração de coliformes termotolerantes acima dessas recomendaçôes. A quantidade de macro e micronutrientes contida nos três efluentes é suficiente para a maioria das culturas cultivadas na região semi-árida do Nordeste do Brasil.

PALAVRAS-CHAVE: Esgoto doméstico, tratamento anaeróbio, pós-tratamento, reúso de água.

\section{INTRODUÇÃO}

A região semi-árida do nordeste do Brasil é caracterizada por apresentar um curto período chuvoso, temperatura elevada e alta taxa de evaporação. Quanto à quantidade de água no solo disponível às plantas, nessa região, registra-se uma deficiência hídrica na grande maioria dos meses do ano. O reúso planejado de águas residuárias domésticas na agricultura vem sendo apontado como uma medida para

\begin{abstract}
The performance of three systems for the post treatment of digested sewage is discussed. The investigated systems were wetlands, rock beds and polishing ponds. The objective of the post treatment was to produce a final effluent for irrigation of cultures in semi-arid areas in North-East Brazil. From the obtained data COD, pH, solids, macronutrients, helminths eggs and thermo tolerant coliforms it was concluded that only polishing ponds were compatible with the WHO recommendation for unrestricted irrigation. Effluents from the wetland and rock bed systems, although free from helminths eggs, contained a higher thermo tolerant coliform concentration than that recommended by WHO. The macro and micronutrient concentrations in all three post treatment systems effluents were high enough for the demand of most cultures in the semi-arid region of North-East Brazil.
\end{abstract}

KEYWORDS: Domestic sewage, anaerobic treatment, post treatment, water reuse.

atenuar o problema da escassez hídrica no semi-árido, sendo uma alternativa para os agricultores localizados especificamente nas áreas circunvizinhas das cidades (Sousa et al, 2003).

As águas residuárias tratadas e destinadas ao reúso agrícola devem ser avaliadas sob os aspectos de sodicidade, salinidade, excesso de nutrientes e, sobretudo, sob os aspectos sanitários: bactérias, cistos de protozoários, ovos de helmintos e vírus que criam graves pro- blemas de saúde pública, uma vez que acarretam enfermidades (Metcalf \& Eddy, 2003). Particularmente, o esgoto doméstico quando utilizado sem tratamento adequado pode contaminar o ambiente, os trabalhadores das áreas cultivadas e os consumidores das culturas irrigadas (Shuval et al, 1997).

Os esgotos detêm teores consideráveis de nutrientes. Estudos realizados por Monte e Sousa (1992); Vazquez-Montiel et al (1996); Mota et al (1997) e Sousa e 
Leite (2003) mostraram que a produtividade $(\mathrm{t} / \mathrm{ha})$ de culturas irrigadas com esgotos tratados foi superior (15 a 30\%) àquela de culturas irrigadas com água de abastecimento e solo adubado com NPK, demonstrando a viabilidade do uso de esgoto na irrigação.

Aspectos relativos à qualidade sanitária e doenças de veiculação hídrica, devido à utilização de esgotos domésticos na agricultura, são tratados na literatura especializada por Feachem et al, (1983); Shuval et al, (1986); Strauss e Blumenthal (1989); Bastos et al (2003). Desta forma, a qualidade sanitária de esgotos tratados tem que ser estabelecida para garantir o uso seguro na irrigação. No Brasil, não existem normas nem critérios próprios para reúso de água de qualidade inferior, apesar da utilização de esgotos domésticos na agricultura ser uma prática milenar realizada em todos os continentes.

$\mathrm{Na}$ falta de normas, seguem-se as recomendações da Organização Mundial da Saúde (OMS, 1989) que, tratandose de irrigação irrestrita, recomenda menos de 1 ovo de helminto por litro e menor ou igual a 1000 coliformes fecais por litro. Essas recomendaçôes parecem muito rigorosas, mesmo tratando-se de irrigação de alimentos que podem ser ingeridos crus, sendo, ao mesmo tempo, omissas em relação aos protozoários e vírus.

Para o uso adequado de esgotos na irrigação se faz necessário o seu tratamento para, além de garantir a qualidade higiênica, corrigir certas características indesejáveis tais como: alta concentração de sólidos e matéria orgânica putrescível.

Reatores anaeróbios de alta taxa, a exemplo do reator UASB - Upflow Anaerobic Sludge Blanked, seguidos de unidades de pós-tratamento, atualmente, vêm sendo largamente utilizados para o tratamento de esgoto doméstico. Nesse contexto, foi realizado um estudo, do qual trata este artigo, sobre o pós-tratamento de efluente anaeróbio em três diferentes sistemas: wetland, leito de brita não vegetado e lagoas de polimento, tendo como finalidade avaliar e comparar a qualidade dos efluentes produzidos para fins de irrigação.

\section{MATERIAL E MÉTODOS}

O experimento foi instalado e conduzido em área pertencente à Companhia de Águas e Esgotos do Estado da Paraíba (CAGEPA), localizada no município de Campina Grande - PB, com coordenadas geográficas de $07^{\circ} 13^{\prime} \mathrm{S}$ e $35^{\circ} 52^{\prime}$ W e altitude de $550 \mathrm{~m}$, onde se localizam a Estação de Tratamento Biológico de Esgotos (EXTRABES) e o grupo de pesquisa do Programa de Pesquisa em Saneamento Básico ( PROSAB).

Foi operado, durante vinte meses, um reator de fluxo ascendente com manta de lodo (UASB), como unidade de tratamento anaeróbio, seguido de três unidades de pós-tratamento, constituídas de wetland, leito de brita não vegetado e lagoas de polimento. O esquema da Figura 1 representa as unidades, estando as características físicas e operacionais apresentadas na Tabela 1.

O reator UASB, fabricado em PVC com volume útil de $5 \mathrm{~m}^{3}$, foi operado com um tempo de detenção hidráulica (TDH) de 6 horas, sendo alimentado com esgoto bruto coletado de um poço de visita do sistema de esgotamento da cidade de Campina Grande, Paraíba - Brasil.

O wetland foi construído em alvenaria e revestido internamente com massa impermeabilizante. Com área de $10 \mathrm{~m}^{2}$ ( $1 \mathrm{~m}$ de largura e $10 \mathrm{~m}$ de comprimento) tinha, como enchimento, areia lavada com granulometria variando de 2,8 a $4,8 \mathrm{~mm}$, formando uma camada de $60 \mathrm{~cm}$, com percentual de vazios de $38 \%$. Com a finalidade de melhorar a distri- buição do fluxo foi depositada, na entrada e na saída, uma camada de cascalho com $40 \mathrm{~cm}$ de largura por $60 \mathrm{~cm}$ de altu$\mathrm{ra}$, com granulometria variando de 15 a $20 \mathrm{~mm}$. O wetland era vegetado com macrófitas do tipo Juncus spp, apresentando uma densidade de 25 propágulos vegetativos por metro quadrado. A vazão de alimentação e o TDH eram, respectivamente, de $0,325 \mathrm{~m}^{3} /$ dia e 7 dias.

O leito de brita foi construído em alvenaria, também com $10 \mathrm{~m}^{2}$ de área (10m de comprimento e $1 \mathrm{~m}$ de largura), tendo como enchimento brita com granulometria variando de 15 a $35 \mathrm{~mm}$, formando uma camada de 0,60 metros de altura e percentual de vazios de $48 \%$. A alimentação era sub-superficial, com uma vazão de $0,411 \mathrm{~m}^{3} / \mathrm{dia}$ o que correspondia a um TDH de 7 dias.

As lagoas de polimento, em número de 5 , totalizaram uma área de $50 \mathrm{~m}^{2}$. Funcionando em série, cada uma com $10 \mathrm{~m}$ de comprimento, $1 \mathrm{~m}$ de largura e $0,60 \mathrm{~m}$ de profundidade útil. O sistema de tratamento UASB mais as lagoas de polimento em série já vinham sendo operados há cerca de três anos. No período de monitoramento, a vazão de alimentação das lagoas (efluente do reator UASB) era de $2 \mathrm{~m}^{3} /$ dia. OTDH total nas lagoas era de 15 dias.

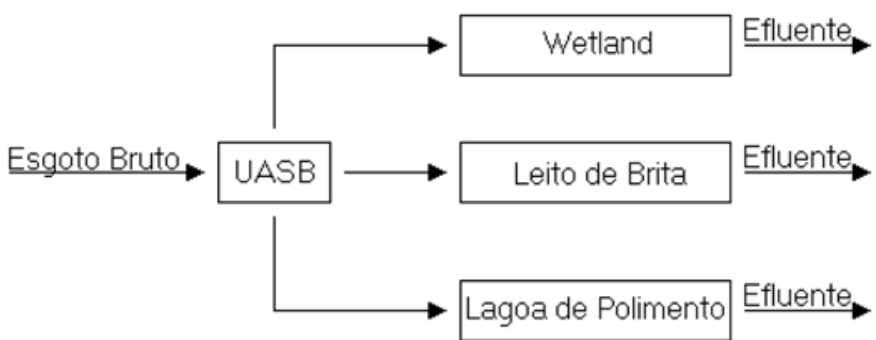

Figura I - Esquema dos sistemas de tratamento operados

Tabela I - Características físicas e operacionais das unidades experimentais

\begin{tabular}{ccccc}
\hline Unidade & \multicolumn{2}{c}{ Dimensóes } & TDH & Vazão \\
& Profundidade $(\mathrm{m})$ & Volume $\left(\mathrm{m}^{3}\right)$ & $(\mathrm{dia})$ & $\left(\mathrm{m}^{3} / \mathrm{dia}\right)$ \\
\hline UASB & 2,50 & 5,00 & 0,25 & 20 \\
Wetland & 0,60 & $2,28^{*}$ & 7 & 0,325 \\
Leito de brita & 0,60 & $2,88^{* *}$ & 7 & 0,411 \\
Lagoas de Polimento & 0,60 & 30,00 & 15 & 2 \\
\hline * volume de vazios $(0,38$ do volume total $)$ & & & \\
** volume de vazios $(0,48$ do volume total $)$ & & &
\end{tabular}


Enquanto os sistemas wetland e leito de brita não vegetado foram operados com fluxo sub-superficial, as lagoas de polimento foram interligadas por tubulações em conexão denominada topofundo, o efluente sai na parte superior e através de tubulação de $20 \mathrm{~mm}$ chega na base inferior onde era distribuído.

As análises físico-químicas e microbiológicas eram realizadas semanalmente e seguiram recomendação do Standard Methods for the Examination of Wastewater (APHA, 1998). A concentração de coliformes termotolerantes foi realizada através da técnica de membrana de filtração que expressa os resultados em Unidade Formadora de Colônias por $100 \mathrm{~mL}$ da amostra, apesar de a WHO (1989), nas diretrizes e recomendações para uso de esgoto tratado na agricultura, recomendar para irrigação irrestrita quantidade de coliformes expressa em Número Mais Provável por $100 \mathrm{~mL}$. Já os ovos de helmintos foram determinados pelo método de Bailenger (WHO,1989). Aos dados obtidos, foi dado um tratamento estatístico, estimando-se medidas de dispersão e de tendência central. Para testar as médias amostrais entre os sistemas de tratamento, foram aplicados métodos estatísticos de inferência com a análise de variância (ANOVA), considerando um nível de significância de 5\%.

\section{APRESENTACÃO E DISCUSSÃO DOS RESULTADOS}

A Tabela 2 apresenta os valores médios e desvio padrão da concentração dos parâmetros determinados, durante o período experimental, no esgoto bruto, efluentes do reator UASB, Wetland, Leito de Brita (L.B) e efluente final das Lagoas de Polimento (L.P).

Já na Tabela 3, estão apresentados os valores médios de nitrogênio, fósforo $\mathrm{e}$ potássio, disponíveis por hectare, a partir dos efluentes do reator UASB, leito de brita não vegetado, wetland e o efluente final das lagoas de polimento. Para estimar a quantidade disponível de cada macronutriente, foram feitas as seguintes consideraçôes: a maioria das culturas regionais tem ciclo vegetativo de 100 dias e atinge uma ótima produtividade com $600 \mathrm{~mm}$ de chuva bem distribuída. Por hectare, o volume de água seria de $6.000 \mathrm{~m}^{3}$ por ciclo da cultura. Considerando, por exemplo, o efluente do reator UASB, o nitrogênio amoniacal disponível seria de $6000 \mathrm{~m}^{3 *} 38,37=230 \mathrm{~kg} /$ ha por ciclo.
$\mathrm{Na}$ Tabela 4, estão apresentadas as espécies de helmintos e a frequiência relativa da presença desses no esgoto bruto e nos efluentes tratados. A partir dessas tabelas, discute-se a seguir os parâmetros analisados.

\section{Nutrientes}

O efluente do reator UASB continha uma alta concentração de nutrientes $\left(50 \mathrm{mgNTK} . \mathrm{L}^{-1}, 7,0 \mathrm{mgP} . \mathrm{L}^{-1} \mathrm{e}\right.$ 25,08mgK. $\left.\mathrm{L}^{-1}\right)$. Nas unidades de póstratamento, as concentraçóes de $\mathrm{N}$ e $\mathrm{P}$ mantiveram-se ainda altas, exceto no efluente final das lagoas de polimento $\left(8,9 \mathrm{mgN}-\mathrm{NH}_{4}{ }^{+} \cdot \mathrm{L}^{-1}\right.$ e $\left.4,71 \mathrm{mgP} \cdot \mathrm{L}^{-1}\right)$. Observa-se que concentraçôes de nitrogênio amoniacal maiores que $30 \mathrm{mg}$. $\mathrm{L}^{-1}$ não são recomendadas para a irrigação e, tratando-se de culturas sensíveis, teores de nitrogênio amoniacal acima de $5 \mathrm{mg} . \mathrm{L}^{-1}$ já causam efeitos negativos para as culturas sensíveis (Ayers e Westcot, 1991). No entanto, quando se observa a Tabela 3, a quantidade de nitrogênio disponível por hectare pode ser insuficiente, por exemplo, para irrigação de gramíneas durante a estação quente e em solos com teor de matéria orgânica menor que $2,5 \%$, que, segundo Malavolta et al (2002), necessitariam de adubação mineral na ordem de $200 \mathrm{kgN} /$ ha por ciclo.

Lagoas rasas, com localização geográfica no Nordeste, possibilitam o aproveitamento de mais de $84 \%$ da radiação incidente, com uma duração média de insolação de 2800h.ano ${ }^{-1}$. Esses fatores favorecem o processo de fotossíntese, reduzindo sobremaneira a concentração de $\mathrm{CO}_{2}$. Com a diminuição da acidez, ocorre a elevação do $\mathrm{pH}$, prevalecendo a fase gasosa da amônia e o desprendimento de gás amônia da fase líquida, associado à precipitação de sais insolúveis de fósforo, tais como a estruvita $\left(\mathrm{Mg}\left(\mathrm{NH}_{4}\right) \mathrm{PO}_{4}\right)$ e apatita $\left(\mathrm{Ca}_{10}(\mathrm{OH})_{2}\left(\mathrm{PO}_{4}\right)_{6}\right)$.

Com relação ao fósforo e ao potássio expressos em $\mathrm{P}_{2} \mathrm{O}_{5}$ e $\mathrm{K}_{2} \mathrm{O}$, respectivamente, estes encontram-se em quantidades consideráveis. No entanto, no caso específico do fósforo, observa-se (Tabela 3) uma menor quantidade para o efluente advindo do sistema wetland.

Sabe-se que o fósforo é um constituinte fundamental que armazena e transfere energia à planta, e sem a presença desse não ocorre nenhum processo metabólico. Sabe-se também que se deve evitar a fixação do fósforo na formação de complexos que a planta não consegue absorver. Segundo Primavesi (2002) três fatores contribuem para manter a disponibilidade do fósforo para a planta: manutenção do $\mathrm{pH}$ perto da neutralidade, solo adequadamente arejado e a permanente incorporação da matéria orgânica que permite a humificação, aumentando o tamponamento e possibilitando a ligação do fósforo em compostos de húmus que mantêm formas de fósforo disponíveis para a maioria das plantas. Dessa forma, a fertirrigação com efluentes tratados fica favorecida devido à constante dose de macronutrientes e matéria orgânica durante todo o ciclo da planta.

\section{Matéria orgânica}

A presença de matéria orgânica no esgoto tratado, nesse trabalho, foi mensurada em termos de Demanda Química de Oxigênio (DQO). A matéria orgânica estabilizada e na forma de húmus exerce efeitos positivos sobre suas propriedades físicas e químicas do solo, além de possibilitar a formação de "grumos" que são agregados secundários constituídos de microrganismos (Primavesi, 2002; Brady, 1989).

Conforme Tabela 2, a baixa concentração de sólidos suspensos voláteis (75 mg SSV.L ${ }^{-1}$ ) e o reduzido valor de DQO (220mg. L $\mathrm{L}^{-1}$ ) apresentados no efluente do reator UASB são fatores que contribuem para que a lagoa de polimento tenha baixa turbidez e apresente maior transparência para a passagem de luz solar, favorecendo desta forma, a intensa atividade fotossintética com grande produção de oxigênio pelas algas.

Cavalcanti (2003) estudando a remoção de matéria orgânica, em diferentes lagoas de polimento em função do tempo de detenção hidráulica, para diferentes profundidades, observou que a DQO oriunda do reator UASB foi rapidamente reduzida na lagoa de polimento, devido, sobretudo, ao processo físico de sedimentação de flocos de lodo anaeróbio. No entanto, à medida que aumentava a profundidade da lagoa, a diminuição da DQO ocorria mais lentamente.

Os efluentes advindos do leito de brita e do sistema wetland apresentaram DQO relativamente baixas, $78 \mathrm{e}$ $60 \mathrm{mgO}_{2} \mathrm{~L}^{-1}$, respectivamente (Tabela 2). A análise de variância (ANOVA), testando os valores médios entre os sistemas de tratamento, não detectou diferença significativa $(\mathrm{p}<0,05)$, entre os efluentes do wetland e do leito de brita. Estes efluentes quando utilizados na 
Tabela 2 - Valores médios e desvio padrão da concentração dos parâmetros determinados no esgoto bruto (EB), efluentes do reator UASB e das unidades de pós-tratamento

\begin{tabular}{|c|c|c|c|c|c|c|c|}
\hline Parâmetros & $\mathrm{n}$ & $\begin{array}{l}\text { Medidas } \\
\text { estatísticas }\end{array}$ & E.B & UASB & L.B & Wetland & L. P \\
\hline $\begin{array}{l}\text { NTK } \\
\left(\mathrm{mg} . L^{-1}\right)\end{array}$ & 30 & $\begin{array}{l}\text { Média } \\
\delta\end{array}$ & $\begin{array}{c}52,23 \\
4,45\end{array}$ & $\begin{array}{l}50,0 \\
6,84\end{array}$ & $\begin{array}{c}34,96 \\
7,98\end{array}$ & $\begin{array}{c}28,03 \\
9,01\end{array}$ & $\begin{array}{l}15,57 \\
4,83\end{array}$ \\
\hline $\begin{array}{l}\text { Nitrogênio } \\
\text { amoniacal } \\
\left(\mathrm{mg} \cdot \mathrm{L}^{-1}\right)\end{array}$ & 30 & $\begin{array}{l}\text { Média } \\
\delta\end{array}$ & $\begin{array}{c}39,52 \\
1,13\end{array}$ & $\begin{array}{c}38,37 \\
7,06\end{array}$ & $\begin{array}{c}30,86 \\
8,63\end{array}$ & $\begin{array}{c}23,52 \\
8,98\end{array}$ & $\begin{array}{l}8,90 \\
7,94\end{array}$ \\
\hline $\begin{array}{l}\text { Fósforo total } \\
\qquad\left(\mathrm{mg} \cdot \mathrm{L}^{-1}\right)\end{array}$ & 30 & $\begin{array}{c}\text { Média } \\
\delta\end{array}$ & $\begin{array}{l}7,09 \\
1,28\end{array}$ & $\begin{array}{l}6,97 \\
0,95\end{array}$ & $\begin{array}{l}4,99 \\
2,33\end{array}$ & $\begin{array}{l}3,03 \\
1,26\end{array}$ & $\begin{array}{l}4,71 \\
0,15\end{array}$ \\
\hline $\begin{array}{l}\text { Ortofosfato } \\
\left(\mathrm{mg} \cdot \mathrm{L}^{-1}\right)\end{array}$ & 30 & $\begin{array}{c}\text { Média } \\
\delta\end{array}$ & $\begin{array}{l}4,51 \\
0,71\end{array}$ & $\begin{array}{l}5,83 \\
1,04\end{array}$ & $\begin{array}{l}3,00 \\
2,42\end{array}$ & $\begin{array}{l}2,68 \\
1,12\end{array}$ & $\begin{array}{c}3,1 \\
1,48\end{array}$ \\
\hline $\begin{array}{l}\text { Potássio } \\
\left(\mathrm{mg} . \mathrm{L}^{-1}\right)\end{array}$ & 30 & $\begin{array}{l}\text { Média } \\
\delta\end{array}$ & $\begin{array}{c}25,08 \\
2,99\end{array}$ & $\begin{array}{c}23,76 \\
3,3\end{array}$ & $\begin{array}{c}25,01 \\
3,47\end{array}$ & $\begin{array}{c}24,36 \\
3,15\end{array}$ & $\begin{array}{l}26,0 \\
1,36\end{array}$ \\
\hline $\begin{array}{l}\text { Sólidos totais } \\
\quad\left(\mathrm{mg} \cdot \mathrm{L}^{-1}\right)\end{array}$ & 30 & $\begin{array}{c}\text { Média } \\
\delta\end{array}$ & $\begin{array}{c}1140 \\
105\end{array}$ & $\begin{array}{l}788 \\
178\end{array}$ & $\begin{array}{l}377 \\
209\end{array}$ & $\begin{array}{c}102 \\
59\end{array}$ & $\begin{array}{c}806 \\
92\end{array}$ \\
\hline $\begin{array}{c}\text { DQO } \\
\left(\mathrm{mg} . L^{-1}\right)\end{array}$ & 40 & $\begin{array}{c}\text { Média } \\
\delta\end{array}$ & $\begin{array}{l}682 \\
129\end{array}$ & $\begin{array}{c}220 \\
40\end{array}$ & $\begin{array}{l}78 \\
20\end{array}$ & $\begin{array}{l}60 \\
18\end{array}$ & $\begin{array}{l}129 \\
63\end{array}$ \\
\hline $\begin{array}{l}\text { Sólidos suspensos } \\
\qquad\left(\mathrm{mg} \cdot \mathrm{L}^{-1}\right)\end{array}$ & 30 & $\begin{array}{l}\text { Média } \\
\delta\end{array}$ & $\begin{array}{l}331 \\
206\end{array}$ & $\begin{array}{l}98 \\
57\end{array}$ & $\begin{array}{l}15 \\
2\end{array}$ & $\begin{array}{l}6 \\
4\end{array}$ & $\begin{array}{l}28 \\
15\end{array}$ \\
\hline $\begin{array}{l}\text { Sólidos suspensos } \\
\text { voláteis }\left(\mathrm{mg} \cdot \mathrm{L}^{-1}\right)\end{array}$ & 30 & $\begin{array}{l}\text { Média } \\
\delta\end{array}$ & $\begin{array}{l}249 \\
150\end{array}$ & $\begin{array}{l}75 \\
51\end{array}$ & $\begin{array}{l}10 \\
2\end{array}$ & $\begin{array}{l}4 \\
3\end{array}$ & $\begin{array}{l}21 \\
15\end{array}$ \\
\hline $\mathrm{pH}$ & 48 & $\begin{array}{l}\text { Média } \\
\text { Máximo } \\
\text { Mínimo }\end{array}$ & $\begin{array}{l}6,71 \\
6,9 \\
6,61\end{array}$ & $\begin{array}{l}6,85 \\
7,04 \\
6,68\end{array}$ & $\begin{array}{l}7,51 \\
7,82 \\
7,26\end{array}$ & $\begin{array}{c}7,41 \\
7,8 \\
7,05\end{array}$ & $\begin{array}{l}8,82 \\
9,20 \\
8,29\end{array}$ \\
\hline $\begin{array}{l}\text { Condutividade } \\
\text { elétrica }\left(25^{\circ} \mathrm{C}\right)\end{array}$ & 30 & $\begin{array}{l}\text { Média } \\
\delta\end{array}$ & $\begin{array}{l}1,648 \\
0,186\end{array}$ & $\begin{array}{l}1,579 \\
0,129\end{array}$ & $\begin{array}{l}1,565 \\
0,111\end{array}$ & $\begin{array}{l}1,517 \\
0,091\end{array}$ & $\begin{array}{r}1,46 \\
0,077\end{array}$ \\
\hline $\begin{array}{l}\text { Cloretos } \\
\left(\mathrm{mg} . \mathrm{L}^{-1}\right)\end{array}$ & 15 & $\begin{array}{l}\text { Média } \\
\quad \delta\end{array}$ & $\begin{array}{c}214 \\
42\end{array}$ & $\begin{array}{c}197 \\
9\end{array}$ & $\begin{array}{c}189 \\
7\end{array}$ & $\begin{array}{c}160 \\
10\end{array}$ & $\begin{array}{c}210 \\
17\end{array}$ \\
\hline $\begin{array}{l}\text { Coliformes } \\
\text { termotolerantes } \\
(\mathrm{UFC} / 100 \mathrm{~mL})\end{array}$ & 28 & $\begin{array}{l}\text { Média } \\
\text { geométrica }\end{array}$ & $1,0 \times 10^{7}$ & $9,8 \times 10^{6}$ & $9,8 \times 10^{3}$ & $7,9 \times 10^{3}$ & $9,2 \times 10^{2}$ \\
\hline
\end{tabular}

Tabela 3 - Valores médios dos nutrientes: nitrogênio, fósforo e potássio contidos nos efluentes e calculados para culturas regionais de 100 dias de ciclo vegetativo

\begin{tabular}{cccc}
\hline Unidades & $\begin{array}{c}\mathrm{N} \\
(\mathrm{kg} / \mathrm{ha})\end{array}$ & $\begin{array}{c}\mathrm{P}_{2} \mathrm{O}_{5} \\
(\mathrm{~kg} / \mathrm{ha})\end{array}$ & $\begin{array}{c}\mathrm{K}_{2} \mathrm{O} \\
(\mathrm{kg} / \mathrm{ha})\end{array}$ \\
\hline UASB & 230 & 80 & 175 \\
Leito de Brita & 185 & 41 & 181 \\
Lagoas de Polimento & 53 & 42 & 188 \\
Wetland & 141 & 37 & 176 \\
\hline
\end{tabular}

fertirrigação têm valores nutritivos (nitrogênio e fósforo) superiores ao efluente da lagoa de polimento, bem como uma DQO mais estabilizada.

Dessa forma, a matéria orgânica estabilizada é fonte de energia para os microrganismos, de forma que a bioestrutura granular aumenta a capacidade de armazenar umidade, reter e fixar fósforo e nitrogênio, aumenta a capacidade de troca de cátions (CTC), ajuda a reter potássio, cálcio, magnésio, entre outros nutrientes disponíveis para a fertirrigação.

\section{Potencial hidrogeniônico - pH}

Um solo é ácido quando possui muitos íons $\mathrm{H}^{+}$e poucos íons de $\mathrm{Ca}^{2+}$, $\mathrm{Mg}^{2+}, \mathrm{K}^{+} \mathrm{e} \mathrm{Na}^{+}$adsorvidos nas suas partículas. Na prática, o $\mathrm{pH}$ torna-se relevante 
quando se conhece a textura e a estrutura do solo. A absorção dos nutrientes pela raiz capilar depende do $\mathrm{pH}$ da água e do solo e da espécie vegetal.

A faixa de $\mathrm{pH}$ adequado à irrigação está entre 6,5 e 8,4. Efluentes de sistemas biológicos de tratamento de esgotos com $\mathrm{pH}$ fora dessa faixa poderão causar desequilíbrios nutricionais à planta (Ayers e Westcot, 1991). Nesse contexto, apenas o $\mathrm{pH}$ do efluente final das lagoas de polimento se encontra fora da recomendação.

Observa-se que os valores do $\mathrm{pH}$ do efluente final das lagoas foram determinados durante o período de maior insolação (entre 12:00 e 14:00 horas), quando a atividade fotossintética era máxima, sendo máximo o consumo de $\mathrm{CO}_{2}$ pelas algas. Conseqüentemente o $\mathrm{pH}$ era máximo nesse período (Cavalcanti et al, 2000; Cavalcanti, 2003). No entanto, o efluente produzido à noite e nos períodos de menor insolação poderia ser utilizado, tendo-se ainda como benefício a redução de perdas por evaporação.

\section{Coliformes termotolerantes}

Das unidades de tratamento investigadas, apenas o efluente final das lagoas de polimento apresentou uma concentração média de coliformes termotolerantes abaixo de $1000 \mathrm{UFC} / 100 \mathrm{~mL}$ (Tabela 2). Efluentes com essas características sanitárias podem ser utilizados na irrigação irrestrita (WHO, 1989).

Observa-se que, especificamente nas lagoas operadas, além da temperatura e do $\mathrm{pH}$ que variaram entre $26^{\circ} \mathrm{C} \pm 2^{\circ} \mathrm{Ce}$ 8,29 e 9,20, as características hidráulicas (pouca mistura) e a pequena profundidade favoreceram o rápido decaimento bacteriano.

Os efluentes oriundos do leito de brita e do sistema wetland apresentaram concentraçôes médias similares de coliformes termotolerantes, $9,8 \cdot 10^{3} \mathrm{e}$ 7,9.10 $10^{3}$ UFC. $\mathrm{mL}^{-1}$, respectivamente. Dessa forma, poderão ser utilizados na fertirrigação de culturas de cereais e forrageiras (WHO, 1989).

O tempo de detenção hidráulica nestes sistemas foi de apenas 7 dias, menos da metade daquele da lagoa de polimento. O decaimento bacteriano, neste caso, deve-se a fatores físicos e químicos como: mecanismo de filtração, fixação de biofilme no substrato, sedimentação, oxidação e sorção devido à presença de matéria orgânica.

\section{Dados parasitológicos}

Ascaridíase é uma das helmintoses de maior prevalência, sobretudo no nordeste do Brasil. Observa-se na Tabela 4 que a espécie Ascaris lumbricoides prevaleceu sobre as outras no esgoto bruto, com frequiência relativa de $56,5 \%$. Valor similar (55\%) foi obtido em esgotos brutos na área do canal de Suez (Stott et al,1997). No efluente do reator UASB a frequiência desses helmintos foi de $61,5 \%$. Não foi observada a presença dos helmintos investigados nos efluentes dos sistemas de pós-tratamento.

A remoção de ovos de helmintos se dá por sedimentação discreta e, portanto, depende da carga hidráulica superficial. Cavalcanti et al (2000), operando lagoa com carga hidráulica superficial de $0,22 \mathrm{~m} / \mathrm{dia}$, não encontrou ovos de helmintos no efluente. Também não foram encontrados ovos de helmintos no efluente das lagoas operadas neste experimento, cuja carga hidráulica superficial foi de $0,20 \mathrm{~m} / \mathrm{dia}$.

Ainda com referência a parasitas, não foi analisada a ocorrência de cistos de protozoários nos efluentes dos sistemas de pós-tratamento. No entanto, segundo a OMS (1989), a ausência de ovos de helmintos nos efluentes pós-tratados indica a remoção de organismos sedimentáveis, incluindo cistos de protozoários, a exemplo de Entamoeba, Giárdia e Cryptosporidium.

\section{CONCLUSÕES}

Embora não removendo significativamente organismos patogênicos e nutrientes, o reator UASB, com TDH de 6 horas, apresentou desempenho na remoção de DQO e SSV superior a 60 e $70 \%$, respectivamente. Essa considerável

Tabela 4 - Quantificação (ovos/L) e freqüência (\%) de ovos de helmintos no esgoto bruto e nos efluentes dos sistemas de pós - tratamento

\begin{tabular}{|c|c|c|c|c|c|c|c|}
\hline \multirow[t]{2}{*}{ Espécies de Helmintos } & \multicolumn{2}{|c|}{$\mathrm{EB}$} & \multicolumn{2}{|l|}{ UASB } & \multirow{2}{*}{$\begin{array}{l}\text { LB } \\
\text { No }\end{array}$} & \multirow{2}{*}{$\begin{array}{c}\text { Wetland } \\
\text { No }\end{array}$} & \multirow{2}{*}{$\begin{array}{l}\text { LP } \\
\text { No }\end{array}$} \\
\hline & No & $\mathrm{F}(\%)$ & No & $\mathrm{F}(\%)$ & & & \\
\hline Ascaris lumbricoides & 202 & 56,5 & 141,4 & 61,5 & 0 & 0 & 0 \\
\hline Trichuris trichiura & 98 & 27,7 & $49,3-$ & 21,5 & 0 & 0 & 0 \\
\hline Ancilostomatideos & 32 & 9,0 & 20,1 & 8,7 & 0 & 0 & 0 \\
\hline Enterobius sp & 12,3 & 5,5 & 10,2 & 4,4 & 0 & 0 & 0 \\
\hline Hymenolepis sp & 9,7 & 2,7 & 8,9 & 3,9 & 0 & 0 & 0 \\
\hline Total & 353,7 & 100 & 229,9 & 100 & 0 & 0 & 0 \\
\hline
\end{tabular}

remoção representa uma significativa diminuição de carga orgânica, favorecendo, portanto, o pós-tratamento em sistemas como Wetland, Lagoas de Polimento e Leito de Brita.

Devido à baixa qualidade higiênica, efluentes de reatores UASB só devem ser usados na irrigação com restrição.

Os sistema wetland, Leito de Brita não vegetado e Lagoas de Polimento, operados sob as condiçóes apresentadas nessa pesquisa, produziram efluentes isentos de ovos de helmintos. Os sistemas wetland e leito de brita apresentaram concentraçôes de coliformes termotolerantes superiores a $1000 \mathrm{UFC} / 100 \mathrm{~mL}$, não sendo, pois, recomendados para uso na irrigação irrestrita, segundo a OMS (1989).

O efluente final produzido nas Lagoas de Polimento apresentou boa qualidade sanitária: baixa concentração de coliformes termotolerantes (menor que 1000 UFC/100mL) e ausência de ovos de helmintos, podendo, pois, ainda segundo a OMS (1989), ser usado na irrigação irrestrita.

Com exceção do efluente final, oriundo das Lagoas de Polimento, a quantidade de macronutrientes contida nos outros três efluentes é suficiente para a maioria das culturas regionais cultivadas na região semi-árida do nordeste do Brasil.

\section{AGRADECIMENTOS}

Os autores agradecem ao CT$\mathrm{HIDRO}$, ao $\mathrm{CNPq}, \mathrm{BNB}$, à Companhia de Águas e Esgotos da Paraíba CAGEPA, à EXTRABES e ao Programa de Pesquisa em Saneamento Básico PROSAB. 


\section{REFERÊNCIAS}

APHA. AWWA. WPCF. Standard Methods for the Examination of Water and Wastewater. 15 ed. Washington, DC.. American Public Health Association. American Water Works Association, Water Pollution control Federation, 1134 p. 1998.

AYERS, R.S; WESTCOOT, D.W. A qualidade de água na agricultura. Trad. Gheyi, H. Medeiros, J. F.; Damaceno, F.V. , Campina Grande, UFPB, 218p. 1991.

BAILENGER, J. Mechanisms of parasitological concentration in coprology and their practical consequences. Journal of American Medical Technology, 41, apud AYRES, R \& MARA, D. Analysis of wastewater for use in agriculture. A laboratory manual of parasitological and bacteriological techniques. Geneva: WHO, p.65-71, 1989.

BASTOS, R.K.X.; BEVILACQUA, P.D.; KELLER. Organismos patogênicos e efeitos na saúde humana. In: Desinfecção de efluentes sanitários. PROSAB 3. Rio De Janeiro-RJ.: ABES. p.27-88, 2003.

BRADY, M.C. Natureza e propriedades dos solos. $7^{\mathrm{o}}$ ed. Rio de Janeiro: Livraria Freitas Bastos, 878p. 1989.

CAVALCANTI, P.F.F., van HAANDEL, A C. , LETTINGA, G. Polishing ponds for post treatment of digested sewage: Sequential batch ponds. In: VI OFICINA SEMINÁRIO LATINO-AMERICANO DE DIGESTÃO ANAERÓBIA. 5-9 nov. Recife-Pe-Brasil, p .352-359, 2000.

CAVALCANTI, P.F.F. Integrated application of the UASB reactor and ponds for domestic sewage treatment in tropical regions. The Netherlands, Thesis Wageningen, University . 139p. 2003.

FEACHEM, R. G. et al. Sanitation and disease - Health aspects of excreta and wastewater management. Washington, D.C. USA: John Wiley \& Sons, 501p. 1983.
MALAVOLTA, E. Métodos para la determinación de deficiencia. In: Fitopatologia - Curso Moderno, Tomo IV. Ed. Por A. A. Sarasola e M. A. R. de Sarasola. Editorial Hemisfério Sur, Buenos Aires. p. 244-247, 1965.

METCALF \& EDDY. Inc. Wastewater Engineering treatment Disposal Reuse. 4. ed. New York, McGraw - Hill Book, 1815p. 2003.

MONTE, M.H.F; SOUSA, M.S. Effect on crop of irrigation with facultative pond effluent. Water Science and Technology, Oxford. v.26, n.7/8, p. 1603-1613, 1992.

MOTA, S; BEZERRA, F. C.; TOMÉ, L. M. Avaliação do desempenho de culturas irrigadas com esgotos tratados. In: 19a. Congresso Brasileiro de Engenharia Sanitária e Ambiental, 1419 set. Foz do Iguaçu, 1997. Rio de Janeiro, ABES, CD-Rom , p. 20-25, 1997.

PRIMAVESI, A., Agricultura em regiöes tropicais. Manejo ecológico do solo. São Paulo: ed. Nobel. 2002. 549p. PAGANINI, W. S. Reúso de água na agricultura. In: Mancuso, P.S.S; Santos, H.F. (ed) Reúso de água. Barueri,SP: Manole, p.338-401, 2003.

SHUVAL, H., ADIN. A. FATTAL, Wastewater Irrigation in Developing Countries. Health Effects and Technical Solutions. World Bank Technical. Paper Number 51, Integrated Resource Recovery Projects series number GLO/80/ 004, Washington, D.C. 324 p. 1986.

SHUVAL, H. et al. Development of a Risk Assessment Approach for Evaluating Wastewater Reuse Standards for Agriculture. Water Science and Technology, Oxford. v. 35, n. 11-12, p. 15-20, 1997.

SOUSA, J. T. de; LEITE, V.D. Tratamento e Utilização de Esgotos Domésticos na Agricultura. Campina Grande: Ed. EDUEP, 135p. 2003.

SOUSA, J. T. de et al. Efluentes tratados utilizados na agricultura. In: XV SIMPÓSIO BRASILEIRO DE RECURSOS HÍDRICOS. Curitiba-PR, Brasil, p.1-12, 2003.
STOOT, R. et al. A survey of the microbial quality of wastewaters in Ismailia, Egypt end the implications for wastewater reruse. Water Science and Technology, Oxford. v. 35, n. 11-12, p. 211-217, 1997

STRAUSS, M. E.; BLUMENTHAL, U.J. Human wastes use in agriculture and aquaculture -Utilisation practises and health prespectives. IRCWR Report n.1/89, 1989.

VASQUEZ-MONTIEL, O ; HORAN, N.J. ; MARA, D.D. Management of wastewater for reuse in irrigation. Water Science and Technology, Oxford. v. 33, n. 10-11, p. 355362,1996 .

WORLD HEALTH ORGANIZATION. Health guidelines for the use of wastewater in agriculture and aquaculture. Technical report series. 778. Geneva: World Health and Organization, 72p. 1989.

\section{Endereço para correspondência:}

\section{José Tavares de Sousa \\ Universidade Estadual da Paraíba \\ Centro de Ciências e Tecnologia \\ Rua Juvêncio Arruda, $s / n^{\circ}$ \\ Campus I, Bodocongó \\ 58 109-753 Campina Grande - PB - \\ Brasil \\ Fax: (83) 33/5-3352 \\ E-mail: tavares@cct.uepb.br}

